\title{
DIE BLECHTROMMEL: NARRADOR LITERARIO ADULTO VERSUS NARRADOR FÍLMICO NIÑO
}

\author{
Juan José Hernández Medina. Universidad de Almería
}

\begin{abstract}
El presente estudio toma como punto de partida la película realizada por el director alemán Volker Schlöndorff Die Blechtrommel (1979), basada en la novela homónima de Günter Grass, para adentrarse en los problemas que supone la traslación a imágenes de una obra literaria compleja y extensa, como es el caso del clásico del Premio Nobel alemán. La adaptación realizada por Schlöndorff constituye un modelo de cómo se puede mantener la fidelidad al espíritu del autor y a la particular visión del protagonista de El Tambor de Hojalata, sin tener que renunciar por ello a la expresión de un lenguaje fílmico personal y sugerente.
\end{abstract}

\section{INTRODUCCIÓN}

Toda adaptación de una obra literaria al mundo cinematográfico supone un largo y dificultoso camino en el que se tiene como fin transformar la palabra escrita en imágenes audiovisuales en movimiento. Sin embargo, en el estudio que nos concierne, en el que analizaremos la versión cinematográfica de la obra más famosa del escritor y Premio Nobel alemán Günter Grass, Die Blechtrommel (1959), no realizaremos un extenso análisis comparativo e interdisciplinar entre las artes literaria y cinematográfica, puesto que ello sería más propio de una tesis doctoral, sino que única y exclusivamente nos ocuparemos del estudio de la transposición de la instancia narrativa desde la novela a la también homónima adaptación cinematográfica realizada por el director Volker Schlöndorff el año 1979. En este sentido, en el primer apartado del presente artículo se ha considerado conveniente ofrecer una resumida visión sobre el método general que utiliza el cineasta al transplantar el contenido temático del referente literario a la gran pantalla.

Tras este primer apartado daremos paso a la producción de la película, en la que cabe destacar la colaboración de Günter Grass, que como es evidente, ayudó sin ninguna duda a aportar una clara visión sobre su novela. A continuación se analizarán el proceso y los factores que intervienen en la consecución de la instancia narrativa propia del discurso fílmico.

En un cuarto apartado nos ocuparemos del problema que ocasionó la búsqueda de un actor idóneo para la interpretación de Oskar Matzerath, el personaje principal y al mismo tiempo figura narrativa del referente literario, cuya integración como narrador en el discurso fílmico mediante los mecanismos del ente cinematográfico será el objeto de estudio final. 


\section{EL DIRECTOR VOLKER SCHLÖNDORFF Y SUS ADAPTACIONES}

Antes del rodaje de Die Blechtrommel el director de cine Volker Schlöndorff había adaptado con éxito un considerable número de obras narrativas a la gran pantalla. Dichas obras literarias le sirven, como él mismo reconoce en una entrevista concedida a Aldo Tassone, de material y fuente de información para realizar sus películas:

Mis experiencias son básicamente la lectura (...) Yo siempre parto de mis experiencias literarias para hacer mis films, primero, porque yo, personalmente, no escribo y segundo, porque cuando he leído un libro necesito desembarazarme de él. Me gusta mucho poner en escena textos, esto me ayuda a encontrar cosas...(Tassone, 1979: 25)

Resulta harto curioso que Schlöndorff no adapte el referente literario, sino que busque el "ímpetu" que tuvo el escritor, es decir lo que le motivó a escribir el libro (Steinborn, 1979: 9). Así pues él busca la verdad sita en el referente literario desde la cual se inspiró el autor: "Ich suche die Wirklichkeit hinter dem Buch, das, wovon der Schriftsteller ausgegangen ist" (Schlöndorff, 1979: 48). Dicha verdad, o mejor dicho, estas ideas, espera el director que renazcan, puesto que tanto él como el escritor se han confrontado con ellas (Steinborn, 1979: 10).

La fuente de información literaria que utiliza para realizar sus filmes se encuentra en la historia alemana (Steinborn, 1979: 9). Centrándose así, como se puede observar en la adaptación objeto de nuestro estudio, en la concentración temática de figuras e historias de un determinado período de la historia de Alemania que encarnan los problemas del país. Caracteres que a menudo son víctimas, que sufren más que sentirse recalcitrantes, pero desarrollan al mismo tiempo una furia y energía que escapa al mero espacio de víctima.

\section{LA PELÍCULA: ASPECTOS GENERALES}

Antes de seguir con el presente estudio, conviene señalar que el filme Die Blechtrommel no es la primera obra de Günter Grass llevada a la gran pantalla, aunque sí la que mayor éxito ha tenido tanto a nivel nacional alemán como mundial; anteriormente, en el año 1966 fue adaptada Katz und Maus por el director Hans Jürgen Pohland. Así pues, la película objeto del presente estudio es la segunda adaptación de una obra del Premio Nobel.

Un filme tan complejo como Die Blechtrommel no se hizo de la noche a la mañana. Hasta su realización pasó un largo periodo de tiempo. Desde la publicación de su novela, Günter Grass recibía cada dos años una oferta para su filmación con las ideas más absurdas. Una de ellas fue la realizada por un director de cine americano que no aceptaba que el niño paralizase su crecimiento con tres años; o mejor dicho, suprimir la construcción central de la perspectiva satírica del "anti-héroe" Oskar Matzerath y sustituirla por una figura real, lo cual hubiese tenido como consecuencia la eliminación de la verdad fundamental del libro: un niño que no quiere crecer y paraliza por ello su crecimiento, quedándose así con la altura de un niño de tres años, aunque mentalmente es como un adulto. Grass rechazó la curiosa, pero muy desacertada, propuesta echando al cineasta:

Einmal kam ein amerikanischer Regisseur, der ganz begeistert von dem Buch sprach, das ging eine Viertelstunde lang; dann aber fragte er: "Mub das unbedingt sein, dab dieser Junge mit drei Jahren sein Wachstum einstellt?" Ich habe ihn rausgeschmissen. (Schlöndorff, 1979: 21) 
Franz Seitz fue uno de los pocos productores del cine alemán de la época en pensar en adaptar la novela al mundo del cine. Durante diez años lo intentó, pero sin éxito. Se interesó por primera vez por la adaptación de Die Blechtrommel ya a principios de 1960, menos de un año después de su publicación. En la Feria de Frankfurt preguntó al autor si le podía ceder los derechos para la película, pero encontró una respuesta negativa (Schlöndorff, 1979: 21).

Un día, muchos años después de que Franz Seitz hubiese pedido a Grass que le permitiese filmar su novela, éste le visitó y le preguntó cómo rodaría la película. El productor escribió un primer guión en el breve espacio de dos meses que contó con la aprobación del autor del clásico de la literatura alemana (Schlöndorff, 1979: 22).

El productor Seitz, quizás consciente de la importante misión "nacional" que le había sido encomendada, después de haber escrito un primer guión para la película, pensó para su filmación en Volker Schlöndorff, que con anterioridad ya había adaptado una novela de Robert Musil (Der Junge Törless, 1966), que contó con la ayuda de su producción.

Quizás lo más interesante sobre la producción de Die Blechtrommel sea la participación del autor del referente literario en la adaptación de su obra al mundo del séptimo arte. Un hecho que lógicamente ayudaría a reflejar con mayor precisión las ideas del texto escrito en el medio audiovisual, especialmente los motivos que llevaron al autor a escribir el libro. La colaboración del autor del referente literario tuvo como consecuencia que participase en la creación de los diálogos y por ello, se podría decir, que casi autorizó el guión.

Como es habitual en el mundo del cine, en el trabajo de escritura de un guión es necesaria la colaboración de varias personas. Por ello, Schlöndorff propuso a Jean-Claude Carriére que colaborase en la realización del filme escrito. El francés, aunque había leído la novela de Grass hacía casi veinte años, aceptó inmediatamente por el reconocimiento que le merecía el autor:

He came right out with it: "Would you like to write a script based on The Tin Drum"? I hadn't read the book in almost twenty years - it had been published in Paris in 1960 - but I still had a powerful impression of Grass's achievement. So I inmediately said yes. (Hugues, 1981: 8)

Sin duda alguna, la colaboración del galo Jean-Claude Carriére resultó ser sumamente positiva. El francés, además de escribir la primera versión del guión con Schlöndorff, aportó su experiencia e ideas en el proyecto.

En todo proceso de adaptación puede aparecer un problema difícil de resolver: el abismo semántico entre lo escrito y lo visto. El lenguaje verbal permite en la novela un discurso coherente y eficaz que en el cine, debido a su diferente naturaleza, ha de ser asumido por los elementos visuales y sonoros. No es de extrañar por tanto que el trabajo de escritura del guión basado en una novela como Die Blechtrommel, que desde su publicación había sido considerada difícil de adaptar, fuese un trabajo largo y duro. Schlöndorff, que posee la fuerza, desde su estética de creador de películas, de adaptar el material, y con ello la capacidad de hacerse cargo de la historia literaria con independencia, además de escribir el filme escrito, se había inspirado, siguiendo su método de trabajo habitual, en la verdad y en las ideas que al escritor le llevaron a redactar el libro. Para ello viajó a Danzig, la ciudad en la que el Premio Nobel pasó su infancia y juventud y el escenario principal del texto literario, para visitar el cosmos del autor y experimentar sus vivencias:

Aquí puedo hacer el salto a Grass, quien también parte de una pequeña calle de la periferia de Danzig, de una tienda que no es más grande que esta habitación y en su 
interior coloca a un pequeño personaje y a partir de ahí comienza a construir el mundo hablando de su experiencia personal. Cuando leí el El tambor de hojalata pensé que era imposible hacer de ella un film, pero cuando comencé a hablar con Grass y vi que todo eso para él no eran grandes fantasías, sino experiencias vividas, y que era sólo de vez en cuando, un poco exagerado en una dirección grotesca, burlesca, épica o irracional, pero que todo recomenzaba siempre en la calle, y fui, y vi que la calle existe, y que la tienda está aún allí, con la misma mancha de la bomba de petróleo en la pared; entonces pensé que si él, partiendo de esa realidad había podido escribir una novela tan fantástica, entonces debía ser posible también al cine, partiendo de los mismos elementos, contar su historia. (Tassone, 1979: 26-27)

\section{UNA INSTANCIA NARRATIVA PROPIA PARA EL DISCURSO FÍLMICO}

Un factor importante en la producción de todo texto, literario o fílmico es dotarle de un esqueleto propio. Como es evidente, todo filme ha de tener una estructura narrativa propia y no basarse en la del referente, contribuyendo así a su poeticidad.

Para tal fin, Jean-Claude Carriére fue el responsable de dotar al guión de una estructura distinta a la del referente literario. La instancia narrativa de la novela causaba problemas en la búsqueda de una estructura. La figura de Oskar como narrador adulto que aparecía en el guión escrito por Franz Seitz fue suprimida por Schlöndorff, consiguiendo así evitar el constante cambio temporal y dotar al texto de un acontecer de los hechos lineal.

Otra solución decisiva para la construcción de la estructura fílmica y justificar con mayor argumentación la supresión de la instancia narrativa del referente literario consistía en suprimir la tercera parte de la novela. Esta medida resultó ser sumamente acertada para el mantenimiento de la unidad fílmica, pues de lo contrario hubiese sido necesario otro actor para representar al personaje de Oskar en el período comprendido entre 1945 y 1959. Lo cual hubiese tenido además como consecuencia una continua retrospectiva. Asimismo dicha instancia narrativa de la novela hubiese entorpecido el acontecer de la trama en caso de ser insertada en el filme.

La supresión de la tercera parte del referente literario trae consigo, como es evidente, una amplia elipsis temática que además sufrió mayores reducciones al ser omitidos otros capítulos y pasajes de los dos primeros libros en los que se basó el guión. Esta forma de proceder fue necesaria porque de lo contrario se corría el peligró de que el filme resultase muy largo, además había capítulos y caracteres como el de Herbert Truczinski, cuya omisión no dañaría el desarrollo de la trama.

\section{4. ¿QUIÉN HA DE INTERPRETAR A OSKAR MATZERATH EN EL DISCURSO FÍLMICO?}

Oskar Matzerath, la figura principal de Die Blechtrommel creaba un gran número de dudas acerca del actor adecuado que pudiese interpretar al antihéroe que había paralizado su crecimiento a la temprana edad de tres años. La solución al problema la encontró el mismo guionista: "I suddenly thought of Chaplin's The Kid. That dreamy, sweet quality of Jackie Coogan was exactly what could make a cinematic character out of Oskar" (Hughes, 1981: 8).

La acertada decisión de que un niño diese vida al Oskar Matzerath fílmico demuestra que la verdad fundamental de la novela iba a ser fielmente adaptada al mundo cinematográfico. El 
haber utilizado a un adulto de muy baja estatura hubiese tenido como consecuencia reducir la película a un análisis de los problemas de un enano, mientras que con un niño el espectador que añora su infancia se puede identificar.

En su búsqueda por un actor que hiciese realidad los motivos fundamentales del libro, Schlöndorff consultó a un médico: "In München erzählt mir Dr. Butenandt vom Sohn eines Schauspielers, den er mir, ohne die ärztliche Schweigepflicht zu verletzen, nennen könne: David Bennent" (Schlöndorff, 1979: 43). Éste era un niño de once años de edad también procedente de una familia de actores, su madre era la bailarina Diana Rou y su padre el actor de cine Heinz Bennent, que ya había actuado con anterioridad en otro filme de Schlöndorff (basado en la novela de Heinrich Böll, Die Verlorene Ehre der Katharina Blum, 1975). El pequeño combinaba rasgos precoces con una parálisis de crecimiento ocurrida a los cuatro años de edad. El director se decanta por él en el mismo momento que lo ve: "Als ich ihn am Strabenrand stehen sehe, weib ich, dab der Darsteller des Oskar Matzerath gefunden ist" (Schlöndorff, 1979: 43). Y al compararlo con otros niños de edades comprendidas entre los tres y los doce años llega a la conclusión de que él es el más pequeño, pero parece el mayor: "Ich photographiere David auf dem Oktoberfest, zusammen mit anderen Kindern zwischen drei und zwölf, um die Gröbenverhältnisse und das Verhalten zu vergleichen. David ist der Kleinste, wirkt aber am ältesten" (Ibid.).

La elección del pequeño David Bennent resultó ser la más acertada para la puesta en escena del personaje Oskar Matzerath. Sus grandes ojos azules que causan gran impresión, rostro maduro y estatura ideal ofrecen las imágenes más aproximadas del famoso protagonista de Die Blechtrommel.

Pero David Bennent no es sólo gracias a su físico el actor ideal para la puesta en escena del personaje Oskar Matzerath, también destaca por su excelente capacidad como actor. Quien haya visionado el filme podrá comprobar la facilidad del pequeño para interpretar con una asombrosa espontaneidad tanto a un personaje de tres años, como a uno de dieciocho o veintiuno. Seguramente dicha espontánea actuación sea debida a que posea problemas similares a los del propio Oskar: como hemos señalado el protagonista de Die Blechtrommel paralizó su crecimiento en su tercer cumpleaños y David Bennent dejó de crecer a la temprana edad de cuatro años.

\section{LA INTEGRACIÓN DE LA INSTANCIA NARRATIVA EN EL DISCURSO FÍLMICO}

Una vez encontrado el actor ideal para la interpretación del protagonista principal, el filme sugiere su integración como figura narrativa por medio de la voz en over, manteniéndose así el carácter literario. Mediante ella el narrador fílmico recita textos basados en la novela, y al contrario que la del adulto narrador del libro, es la de un niño pequeño, el actor David Bennent. De esta forma se mantiene al protagonista como comentador, no para dar información, sino para expresar en algunas ocasiones sus pensamientos y opiniones sobre lo que ocurre. Del mismo modo actúa como un mecanismo recordatorio de sucesos que ha vivido Oskar, dando así la impresión de que el discurso fílmico, al igual que el literario, se desarrolla como una autobiografía.

No obstante, pese a narrar a veces los hechos e ideas y desarrollar el carácter autobiográfico, no se logra el efecto de aportar una visión personal desde la perspectiva del principal protagonista que el referente literario sí consigue transmitir; aunque según el director, se pretende mantener de forma más explícita al protagonista como instancia narrativa principal; asimismo los textos recitados en over por David obligan al espectador a escuchar con una gran atención.

Odisea, $n^{0} 1,2001$ 
Además del efecto de reflexión que produce, este último aspecto actúa como elemento indicador del flujo temporal y como advertencia de lo que va a suceder. Un ejemplo de ello es cuando Oskar arrastra a Jan a la Oficina Postal polaca. No es desdeñable la apreciación de que la voz en over pueda resultar redundante al correr paralelamente a la sucesión de las imágenes, pero también puede servir como elemento complementario de la historia, logrando así en diversas situaciones suplir los vacíos que pueda dejar la imagen.

La otra forma de integrar la instancia narrativa se realiza con la cámara subjetiva. Mediante su empleo se contribuye a ofrecer una equivalencia con las primera y tercera personas que utiliza Oskar para expresarse en el referente literario. Algo lógico, puesto que las palabras del narrador en el referente literario han de ser sustituidas por imágenes en el cine. Para ello en el filme se ha buscado la posición acertada para cada plano, situando en numerosas ocasiones el aparato de filmación a la altura de los ojos de Oskar.

Por último, nos permitimos añadir como parte inherente del esqueleto fílmico y por consiguiente de la instancia narrativa el mismo físico del joven actor David Bennent.

\section{CONCLUSIONES}

La voz de fuera de campo de Oskar, el físico del pequeño David Bennent y la cámara deberían ser considerados conjuntamente como la instancia narrativa en el texto fílmico. Asimismo, dicha posición narrativa ha contribuido a emancipar el filme completamente de su referente literario, quizás más de lo que se había pretendido originalmente; además, la combinación de la cámara subjetiva con la voz over logran el efecto de identificación con la figura narradora de la novela y con el texto; pero, como se advierte en párrafos anteriores, la instancia narrativa no es más que una mera sugerencia de la posición narrativa de la novela aunque mantenga en el discurso fílmico el carácter literario. Este cambio en la posición del narrador, marca asimismo la principal diferencia entre el referente literario y el texto fílmico, además del hecho de que ambas artes ya son medios de expresión de distinta naturaleza; el Oskar literario es un adulto de treinta años, un enano, jorobado, paciente de un sanatorio mental, donde está confinado por ser sospechoso de asesinato. La frase que abre la novela impregna su sombra en todo el relato: "Zugegeben: ich bin Insasse einer Heil- und Pfleganstalt, mein Pfleger beobachtet mich, läbt mich kaum aus dem Auge . ..” (Grass, 1959: 9). En la película es una persona completamente diferente: una concretización del Oskar niño que aparece en el referente literario hasta 1945. El actor Bennent encarna nuestra imaginación de la figura a través de su fisonomía, su forma de expresarse, y también en otros aspectos, hecho que tiene como consecuencia que la acción se perciba a través de los ojos de un niño de tres años, al contrario que en el referente literario donde es vista por medio de un adulto.

En el referente, otra de las muchas dificultades con las que se topa el lector es que un hombre aparentemente perverso y desequilibrado medita sobre el pasado desde la perspectiva de un niño. La total falta de moral del narrador provoca un efecto distanciador que hace imposible que el receptor se identifique con el Oskar o con algún otro protagonista de la novela. En el texto fílmico la orientación es más fácil, el receptor fílmico puede identificarse con el niño. Por otra parte, el Oskar fílmico no es un narrador omnisciente, no está internado en un sanatorio mental y tampoco reflexiona sobre sus orígenes y su vida, creando incertidumbre en el receptor fílmico que no sabe cómo acabará la historia. 


\section{BIBLIOGRAFÍA}

Barudio, G. 1979. "Interview mit Günter Grass". Filmfaust, 14: 19-40.

Grass, G. 1959. Die Blechtrommel. Darmstadt/ Neuwied: Luchterhand.

Hicketier, K. 1989. "Der Film nach der Literatur ist Film”. Literaturverfilmungen., Eds. F. Albersmeier und V. Roloff. Frankfurt am Main: Suhrkamp Verlag. 183-198.

Hughes, J. 1981. "The Tin Drum: Volker Schlöndorff's 'Dream of Childhood'”. Film Quaterly 34, 3: 2-10.

Peña, Peña-Ardid, C. 1992. Literatura y Cine. Madrid: Cátedra.

Protzel, J.1982. "El tambor de hojalata". Hablemos de Cine 18, 75: 81-82.

Scherer, M. 1978. "Ein Kuckucks-Küken in der Kaschubei”. Der Spiegel, 45.

Schlöndorff, V. 1979. Die Blechtrommel: Tagebuch einer Verfilmung. Darmstadt: Luchterhand Verlag. 1988. "David Bennent und Oskar Matzerath". Augenzeugen: 100 Texte neuer deutscher Filmemacher. September 1978. Eds. H. H. Prinzler und E. Reutschler . Frankfurt am Main: Verlag der Autoren: 370-371.

Steinborn, B. 1979. "Interview mit Volker Schlöndorff”. Filmfaust, 14: 3-18.

Tassone, A. 1979 . "Entrevista con Volker Schlöndorff”. Dirigido Por..., 68: 24-31. 